\title{
Percepção de gestantes, profissionais de saúde e representantes do ensino superior na prática em grupo
}

\author{
Perception of pregnant women, health professionals and representatives of higher education \\ in group practice
}

\author{
Samantha Ferreira da Costa Moreira ${ }^{1}$ \\ Lucila Pessuti Ferri ${ }^{2}$ \\ Bruno Bordin Pelazza ${ }^{3}$ \\ Guilherme Silva Mendonça ${ }^{4}$ \\ Cacia Regia de Paula ${ }^{5}$
}

\section{RESUMO}

Este estudo de extensão universitária teve como objetivo mostrar a percepção de gestantes, equipe multiprofissional, docentes e discentes sobre a prática de grupo com gestantes da Estratégia de Saúde da Família de um município do sudoeste goiano. Participaram 15 professores da Universidade Federal de Jataí (UFJ), 15 acadêmicos, 6 agentes comunitários de saúde, 6 profissionais da Secretaria Municipal de Saúde, 20 gestantes, além de companheiros e/ou outro familiar. Foram realizadas atividades educativas com metodologias ativas uma vez por mês, com duração de 15 meses. Foi disponibilizado lanche e sorteados brindes e cestas básicas às gestantes em situação de vulnerabilidade social e econômica, com intuito de motivá-las a comparecer ao grupo. Portanto, a percepção dos participantes (gestantes, enfermeiros, docentes e discentes) sobre as atividades educativas foi a construção do saber, de promover o autocuidado e empoderamento das gestantes. A experiência contribuiu para o avanço do ensino-aprendizagem dos alunos.

Palavras-chave: Relações comunidade-instituição. Educação em saúde. Gestantes.

\section{ABSTRACT}

This university extension study aimed to show the perception of pregnant women, a multidisciplinary team, teachers and students about the group practice with pregnant women of the Family Health Strategy of a municipality in the southwest of Goiás, Brazil. 15 professors from the Federal University of Jataí (UFJ) participated, 15 academics, six community health agents, six professionals from the Municipal Health Department, 20 pregnant women, in addition to companions and/or another family member. Educational

\footnotetext{
${ }^{1}$ Doutoranda em Educação na Universidade Federal de Mato Grosso do Sul, Brasil; professora no Centro Universitário de Mineiros, Goiás, Brasil (samanthafrmoreira@ hotmail.com).

${ }^{2}$ Doutoranda em Enfermagem na Universidade Federal de Goiás, Brasil; professora na Universidade Federal de Jataí, Goiás, Brasil (cilapessuti@bol.com.br).

${ }^{3}$ Doutor em Ciências da Saúde pela Universidade Federal de Uberlândia, Minas Gerais, Brasil, com estágio pósdoutoral na Associação de Estudos e Pesquisas aos Portadores de Alzheimer, Paraná, Brasil; professor na Universidade Estadual do Centro-Oeste, Paraná, Brasil (brunobordin@unicentro.br).

${ }^{4}$ Doutorando em Ciências da Saúde na Universidade Federal de Uberlândia, Minas Gerais, Brasil; professor na Universidade Presidente Antonio Carlos, Minas Gerais, Brasil; enfermeiro da Unidade de Internação em Saúde Mental do Hospital de Clínicas da Universidade Federal de Uberlândia, Minas Gerais, Brasil. (guilherme.silva@ufu.br).

5 Doutoranda em Enfermagem na Universidade Federal de Goiás, Brasil; professora assistente da Universidade Federal de Jataí, Goiás, Brasil. (cregia@ufg.br).
} 
activities were carried out with active methodologies once a month, lasting 15 months. Snacks, gifts and basic baskets were made available to pregnant women in situation of social and economic vulnerability, in order to motivate them to attend to the group. Therefore, the perception of participants (pregnant women, nurses, teachers and students) about educational activities was the construction of knowledge, of promoting self-care and empowerment of pregnant women. The experience contributed to the advancement of student's teachinglearning.

Keywords: Community-institutional relations. Health education. Pregnant women.

\section{INTRODUÇÃO}

A assistência à saúde deve ser desenvolvida antes mesmo do indivíduo nascer. A gestação marca a vida da mulher, influencia sua percepção de imagem corporal, sendo necessária adaptação física, emocional, existencial e também sexual. Com essas transformações, é imprescindível a reorganização na vida da gestante, para conciliar o papel de gestante e mulher, e nas atividades desempenhadas na comunidade (PICCININI et al., 2008; GANDOLFI et al., 2019).

Além das mudanças orgânicas que a mulher sofre, o útero pede cuidados especiais durante este período, ocasionando mudanças corporais, emocionais, para adaptar-se ao novo papel que lhe é dado (LEITE et al., 2014). O cuidado à saúde, com a realização de exames recomendados, detecção e tratamento das alterações, no processo gravídico-puerperal, tem como atribuição a prevenção das complicações para o bebê e para a mãe, o que contribui para o desfecho favorável perinatal (DOMINGUES et al., 2012; LIVRAMENTO et al., 2019).

O período gestacional é singular na vida da mulher e remete à experiência excepcional, como o nascimento do filho, o qual merece ser tratado de forma especial pela equipe, sociedade e multiprofissionais de saúde (VIEIRA, 2011).

De acordo com Silva et al. (2015), as gestantes são influenciadas por mitos propagados por familiares e sociedade, sendo fundamental a assistência pré-natal realizada por profissionais da saúde para a desmitificação desses mitos. É importante o acompanhamento do desenvolvimento do feto e esclarecer possíveis dúvidas da mãe, pois mesmo com vivências anteriores, cada gravidez representa atendimento integral, individualizado e humanizado (LEITE et al., 2014). 
O acompanhamento qualificado do pré-natal, elaborado com informações embasadas em estudos científicos, esclarecimento de dúvidas, resolubilidade dos problemas diversos e compartilhamento do plano de cuidado nas várias fases da gestação até o parto, fortalece o vínculo e a confiança do paciente, além de possibilitar que sentimentos como medo, insegurança, ansiedade e angustia sejam amenizados (MARTINS; REMOALDO, 2014).

A assistência pré-natal é um importante componente da atenção à saúde das mulheres no período gravídico-puerperal (VIELLAS et al., 2014). O estudo de Leal et al. (2020) traz que a atenção básica, como ordenadora do cuidado, deve melhorar a qualidade do pré-natal, para obter a redução das taxas de morbidade e mortalidade infantil. Dessa maneira, a equipe multiprofissional humanizada deve ser capacitada para a demanda da população, porém a falta de capacitação afeta o acompanhamento ao pré-natal e ameaça o direito à saúde (SILVA et al., 2014).

A Lei $\mathrm{n}^{\circ}$ 8.080, de 19 de setembro de 1990, traz que a assistência às pessoas deve ser realizada por intermédio de ações de promoção, proteção e recuperação da saúde, com a realização integrada das ações assistenciais e das atividades preventivas. As ações de promoção e educação em saúde contribuem para o empoderamento da mulher e para a efetividade e humanização do cuidado no pré-natal (BARRETO et al., 2015). Dessa forma, educar para a saúde é dar prioridade a ações de prevenção e de promoção a saúde, em espaços coletivos, por meio de grupos educativos. Práticas realizadas rotineiramente durante essa assistência estão associadas a melhores desfechos perinatais (BARROS et al., 2010).

As ações educativas devem superar o modelo biomédico, de modo que valorizem as reais necessidades da gestante em seu contexto de vida e saúde (LANDERDAHL et al., 2007). No estudo de Dias e colaboradores (2015), as gestantes identificam a educação em saúde como ação importante para garantir uma assistência integral durante o pré-natal.

Diante do exposto, com a preocupação em integrar ações assistenciais com atividades preventivas para as gestantes, com ênfase na redução da mortalidade infantil, buscou-se por realizar essa ação de extensão. Haja vista que a extensão universitária representa o vínculo entre a prática dos ensinamentos vivenciados entre a universidade e comunidade (FARIAS et al., 2019). 
Nessa perspectiva, esse estudo teve como objetivo mostrar a percepção de gestantes, equipe multiprofissional, docentes e discentes sobre a prática de grupo com gestantes da Estratégia de Saúde da Família (ESF) de um município do sudoeste goiano.

\section{METODOLOGIA}

O projeto foi proposto pelos docentes do curso de Enfermagem da Universidade Federal de Jataí (UFJ), e foi desenvolvido com gestantes cadastradas que realizavam o pré-natal na ESF das áreas 317 e 309 de um município do interior do Estado de Goiás.

Os proponentes do projeto realizaram dois encontros iniciais: um encontro com os profissionais de saúde que compõem as ESF das áreas 317 e 309 do município; e outro encontro com as gestantes dessas equipes com o intuito de: dividir os participantes do projeto em equipe para buscar patrocínio/doação como brindes, fotografias, entre outros; apresentar às gestantes a proposta do projeto de extensão "Cuidando com saúde"; e conhecer as necessidades, os anseios e as curiosidades das gestantes sobre o período gestacional, parto e puerpério, bem como definir a periodicidade dos encontros e duração, entre outros.

Após esses encontros, definiu-se que as atividades seriam realizadas uma vez por mês, com duração de 15 meses, início em setembro de 2017 e término em novembro de 2018, sempre na última quinta-feira de cada mês. Foi estabelecido o fornecimento de lanches e sorteios de brindes às gestantes participantes, no intuito de motivá-las a comparecer ao grupo.

Ao término das atividades houve oferta de oficina de trabalhos manuais (pinturas de fraldas, confecção de lembrancinhas de biscuit, entre outros), além disso, foi sorteada uma cesta básica às gestantes carentes identificadas pelos Agentes Comunitários de Saúde (ACS).

O conteúdo programático, demonstrado no Quadro 1, foi baseado nos temas propostos pelas próprias gestantes e ministrado por profissionais da Secretaria Municipal da Saúde (SMS) dentre eles: enfermeiros, odontólogos, psicólogos, nutricionistas, médicos, professores do curso de Enfermagem, Psicologia e Fisioterapia da UFG-Regional Jataí e acadêmicos dos referidos cursos. Em todos os encontros, os participantes concederam autorização de participação para uso de imagem, bem como a transferência dos direitos autorais dos depoimentos para fins de publicação em eventos, congresso e revistas. 
O projeto foi submetido à câmara de extensão da UFG-Regional Jataí, a qual hoje, após a emancipação da UFG se tornou UFJ, e recebeu aprovação, conforme registro CISAU-JATPJ541-2017.

\section{RESULTADOS E DISCUSSÃO}

O projeto foi desenvolvido por meio da parceria entre as Secretarias Municipais de Promoção Social, Educação e Saúde do município de Jataí e UFG-Regional Jataí. Participaram 15 professores, 15 acadêmicos, 6 ACS, 6 profissionais da SMS e 20 gestantes, além de esposos e/ou outro familiar. Todos os participantes receberam certificados de participação emitidos pela Pró-reitoria de Extensão e Cultura (PROEC) da UFG.

Segundo estudo realizado por Polgliane e colaboradores (2014), ainda há uma grande falha na assistência de qualidade. Cerca de $30 \%$ das gestantes relataram não ter recebido nenhuma orientação sobre aleitamento exclusivo até o sexto mês de vida durante o acompanhamento do pré-natal, isso demonstra o quão falho ainda é o acompanhamento durante a gravidez numa capital brasileira. O estudo realizado por Rocha e Andrade (2017), identificou como problemas relatados pelas gestantes a escassez de palestras pertinentes à gestação e a espera por atendimento.

Portanto, é importante o estímulo de atividades educativas em grupo ou métodos que proporcionem o protagonismo e o empoderamento da gestante, seja por um processo mútuo de ensinar e aprender, seja pelo incentivo ao diálogo coletivo, com troca de experiências entre os pares (GUERREIRO et al., 2014). Sendo assim, ouvir a gestante e seus familiares sobre os temas a serem abordados e associá-los aos temas que o Ministério da Saúde propõe para as ações educativas com gestante (BRASIL, 2012), foi uma preocupação do grupo de trabalho do projeto. No Quadro 1, verificam-se os conteúdos abordados com o grupo e metodologia de ensino utilizada.

Quadro 1 - Conteúdo programático e metodologias de ensino desenvolvidas no projeto de extensão “Cuidando com saúde”, Jataí-GO, Brasil, 2019

\begin{tabular}{|l|l|}
\hline Atividade de ensino & Tema \\
\hline 1. Roda de conversa & Importância do pré-natal; cuidados de higiene. \\
\hline
\end{tabular}




\begin{tabular}{|c|c|}
\hline 2. Demonstração prática & $\begin{array}{l}\text { Prática de atividade física na gestação, de acordo com os } \\
\text { princípios fisiológicos específicos. }\end{array}$ \\
\hline $\begin{array}{l}\text { 3. Aula expositiva com } \\
\text { oferta de café da manhã }\end{array}$ & $\begin{array}{l}\text { Orientação nutricional (alimentação saudável, suplementação de } \\
\text { ferro, ácido fólico e vitamina A); desenvolvimento da gestação } \\
\text { (etapas). }\end{array}$ \\
\hline 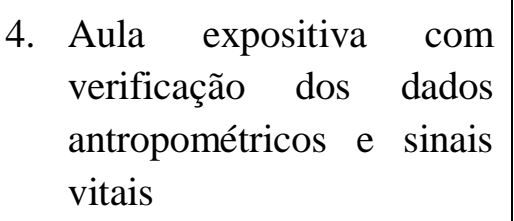 & Doenças crônicas na gestação (hipertensão, diabetes). \\
\hline 5. Roda de conversa & $\begin{array}{l}\text { Modificações corporais e emocionais; medos e fantasias } \\
\text { referentes à gestação e ao parto; orientações sobre saúde mental } \\
\text { e violência doméstica. }\end{array}$ \\
\hline $\begin{array}{l}\text { 6. Aula expositiva com } \\
\text { testes rápidos }\end{array}$ & $\begin{array}{l}\text { Prática de atividade sexual, prevenção das DST/AIDS e } \\
\text { aconselhamento para o teste anti-HIV. }\end{array}$ \\
\hline 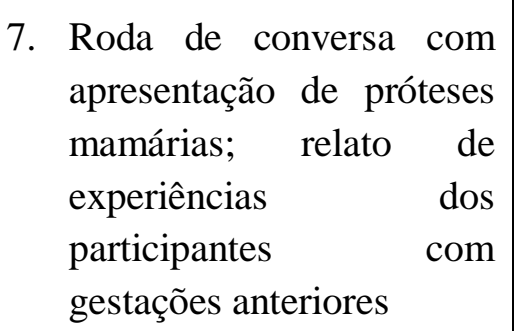 & $\begin{array}{l}\text { Gestação; preparo para o parto (tipos de partos, sinais e sintomas } \\
\text { do parto, planejamento individual, transporte, recursos } \\
\text { necessários, apoio familiar e social; incentivo para o parto } \\
\text { normal); orientações sobre o puerpério; orientações e incentivo } \\
\text { para o aleitamento materno; orientações específicas para as } \\
\text { mulheres que não poderão amamentar. }\end{array}$ \\
\hline $\begin{array}{l}\text { 8. Aula expositiva com } \\
\text { exposição dos métodos } \\
\text { contraceptivos }\end{array}$ & Importância do planejamento familiar. \\
\hline $\begin{array}{l}\text { 9. Aula expositiva r com } \\
\text { boneca, banheiras para } \\
\text { prática do banho dos } \\
\text { recém-nascidos }\end{array}$ & $\begin{array}{l}\text { Cuidados após o parto com a mulher e com o recém-nascido; } \\
\text { retorno aos serviços de saúde para consulta de puerpério e } \\
\text { puericultura; importância dos testes de triagem (teste do } \\
\text { pezinho, teste do olhinho, teste da orelhinha). }\end{array}$ \\
\hline $\begin{array}{l}\text { 10. Aula expositiva com } \\
\text { utilização de bonecos }\end{array}$ & Acidentes comuns na infância; primeiros socorros. \\
\hline 11. Aula expositiva & $\begin{array}{l}\text { Benefícios legais a que a mulher tem direito; Lei do } \\
\text { Acompanhante. }\end{array}$ \\
\hline $\begin{array}{l}\text { 12. Aula expositiva com } \\
\text { atualização dos cartões de } \\
\text { vacinação } \\
\text { participantes }\end{array}$ & Vacinação da gestante e do recém-nascido. \\
\hline 13. Aula expositiva & Desenvolvimento infantil ( 0 a 12 meses). \\
\hline
\end{tabular}




\begin{tabular}{|l|l|}
\hline 14. Aula expositiva & Doenças mais comuns na infância. \\
\hline $\begin{array}{l}\text { 15. Aula expositiva com } \\
\text { relato de experiência das } \\
\text { gestantes, acompanhantes } \\
\text { e pais }\end{array}$ & $\begin{array}{l}\text { Os sintomas comuns na gravidez e orientações para as queixas } \\
\text { mais frequentes; sinais de alerta e o que fazer nessas situações } \\
\text { (sangramento vaginal, dor de cabeça, transtornos visuais, dor } \\
\text { abdominal, febre, perdas vaginais, dificuldade respiratória e } \\
\text { cansaço). }\end{array}$ \\
\hline
\end{tabular}

Fonte: CISAU-JAT-PJ541-2017.

Segundo o Ministério da Saúde, o cuidado pré-natal é a incorporação de condutas acolhedoras e utilização de ações educativas, preventivas, sem influências desnecessárias (BRASIL, 2005; 2012). A educação em saúde pode ser ferramenta de atuação em saúde por possibilitar a troca entre o conhecimento técnico e popular, com o desenvolvimento de ações de prevenção e controle de doenças que possam vir a se instalar (TRAESEL et al., 2004).

No desenvolvimento das atividades educativas, para explanação do conteúdo, utilizaram-se metodologias ativas (Quadro 1), dinâmica de grupo, psicodrama, psicologia cognitivo comportamental, aula expositiva, filmes para discussão, além de roda de conversa. $\mathrm{O}$ momento foi oportuno para que as gestantes sanassem dúvidas e relatassem suas experiências em relação à gestação atual ou anterior.

Por meio das metodologias empregadas pelos professores e profissionais de saúde, a educação popular e a troca de experiências (FREIRE, 2005) utilizadas no diálogo informal, foi possível a apropriação do conhecimento pelos participantes (gestantes e familiares), sem descaracterizar o popular, e também estimular os acadêmicos a aprenderem o conteúdo a ser trabalhado previamente para, dessa maneira, entenderem que cada gestação é única e provoca inseguranças por parte das gestantes.

A participação dos profissionais no grupo de gestantes, aliada ao uso de práticas educativas ativas, remeteu à percepção do fortalecimento de ensinamentos/conhecimentos como colaborador da formação de profissionais de enfermagem conscientes e humanitários. Aos discentes coube a percepção das gestantes estarem passando por um momento de transformação e, na comparação das dúvidas, as das multíparas em relação às primíparas eram as mesmas. 
Quadro 2 - Depoimento dos participantes sobre o projeto "Cuidando com saúde”, Jataí-GO, Brasil, 2019

\begin{tabular}{|c|c|}
\hline Participantes & Depoimentos \\
\hline Docente 1 & $\begin{array}{l}\text { "As atividades buscaram uma atenção intersetorial, conseguimos nessa } \\
\text { parceria realizar ações direcionadas às gestantes em situação de } \\
\text { vulnerabilidade social e econômica". }\end{array}$ \\
\hline Docente 2 & $\begin{array}{l}\text { "A importância deste projeto foi tamanha, pois se estendeu aos } \\
\text { familiares. Atividades de rastreamento e detecção foram oferecidas e os } \\
\text { casos alterados direcionados para atendimento, estreitando os laços com } \\
\text { as gestantes". }\end{array}$ \\
\hline Discente 1 & $\begin{array}{l}\text { "A minha percepção é a transferência de conhecimento a um público } \\
\text { que se encontra em um momento de transformação e que dúvidas } \\
\text { surgem; compreendi que as dúvidas e a insegurança têm o mesmo nível } \\
\text { entre as mulheres que estavam na primeira gestação e as demais". }\end{array}$ \\
\hline Gestante 1 & $\begin{array}{l}\text { "Eu me lembrava em todo o tempo da fala dos profissionais que deram } \\
\text { o curso de gestantes, sobre a hora certa de fazer força. Então, tentava } \\
\text { fazer força na hora que meu corpo pedia e a dor diminui muito". }\end{array}$ \\
\hline Gestante 2 & $\begin{array}{l}\text { "Eu achei que estas coisas de grupo eram uma besteira e de tanto } \\
\text { insistirem fui. À noite, meu bebê deu sinal e me lembrei de tudo que foi } \\
\text { falado à tarde no grupo. Meu bebê nasceu super-rápido". }\end{array}$ \\
\hline Profissional 1 & $\begin{array}{l}\text { "Com o uso dessa metodologia de ensino me senti protagonista do } \\
\text { ensino e da aprendizagem". }\end{array}$ \\
\hline Profissional 2 & $\begin{array}{l}\text { "Notei que essa metodologia incentivou os acadêmicos para que } \\
\text { aprendessem de forma autônoma e participativa, a partir de problemas e } \\
\text { situações reais". }\end{array}$ \\
\hline
\end{tabular}

Fonte: CISAU-JAT-PJ541-2017.

O sorteio de cestas básicas e a oficina de trabalho manual, promovidos pela Secretaria Municipal de Promoção Social, foram uma forma de incentivo para que as gestantes e seus familiares participassem do projeto, além de auxiliar gestantes em situação de vulnerabilidade social e econômica (Figura 1). 
Figura 1 - Participação de gestantes, ACS e docentes no projeto "Cuidando com saúde", Jataí-GO, Brasil, 2019

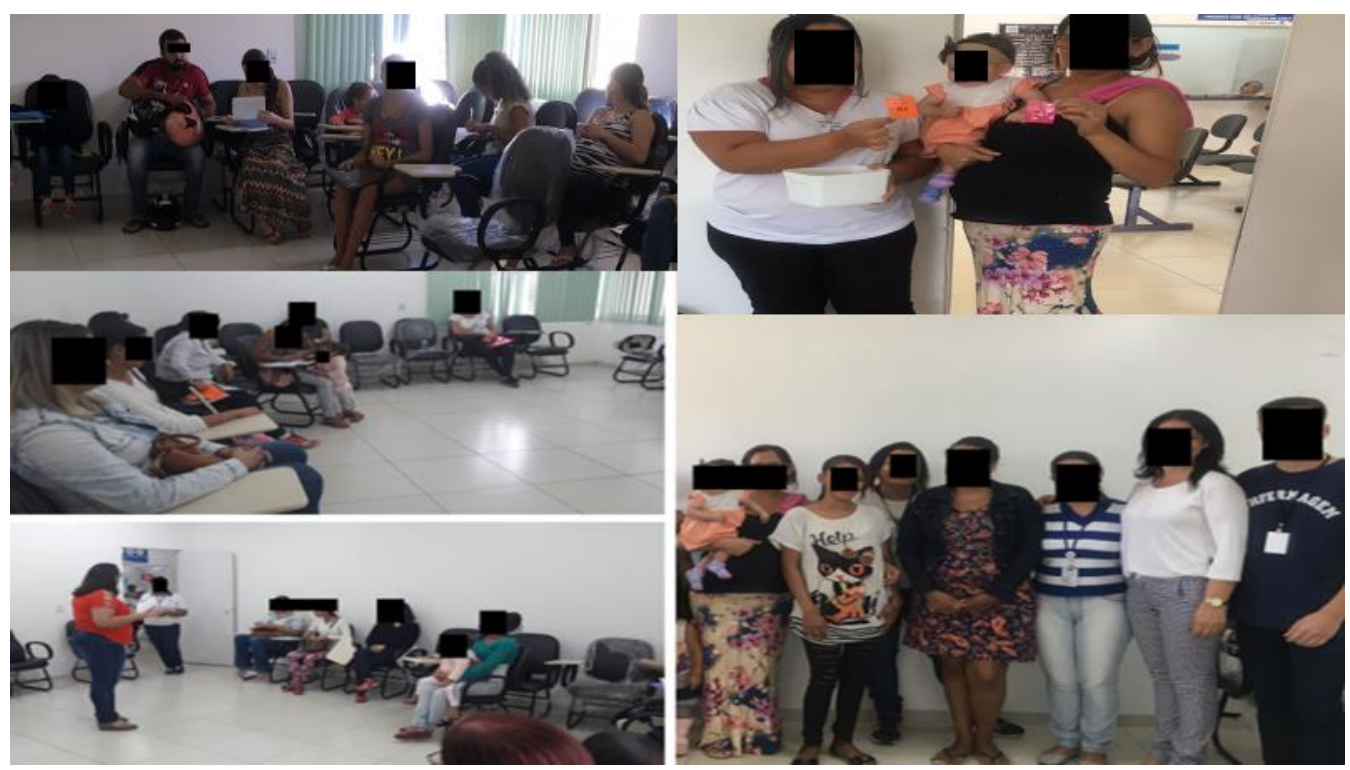

Fonte: CISAU-JAT-PJ541-2017.

Em todos os encontros do grupo de gestantes foi observada a presença dos companheiros e/ou outro familiar, ACS, enfermeiros, docentes e discentes (Figura 1). A educação em saúde no pré-natal foi importante para o grupo, no sentido de poder falar sobre suas preocupações, angústias, consolidar informações importantes sobre a saúde da criança, da mulher e da família (BRASIL, 2012).

A atenção obstétrica e neonatal deve ter como característica a humanização. Diante disso, é importante ressaltar a necessidade de estabelecer um vínculo entre a gestante e os profissionais da saúde (BRASIL, 2005). No estudo de Dias et al. (2018), as gestantes valorizam o profissional enfermeiro ao buscar estratégias para reforçar as ações de educação em saúde e, assim, melhorar a assistência a elas e a conexão entre a comunidade e o serviço de saúde.

Para Domingues, Jordão e Castilho (2019), a extensão é um método educativo, cultural e científico de mão dupla, que oportuniza um espaço de produção de novos saberes quando articulada com o ensino e a pesquisa, numa concepção transformadora e crítica. Diante do exposto, iniciativa como a mostrada neste texto mostra que atividades de extensão que utilizam metodologias ativas, formas lúdicas e divertidas de aprendizado aproximam usuários, 
profissionais, docentes e acadêmicos do conhecimento, e faz com que todos se sintam como parte do processo de ensino aprendizagem, além de valorizados e motivados a aprender.

Assim, os participantes irão se empoderar de conhecimento proveniente da educação em saúde e, consequentemente, mudar os costumes da comunidade e fortalecer esse contexto para as gerações futuras.

O projeto apresentou limitação no número de participantes, entretanto demonstrou potencialidade das ações de educação em saúde como ferramenta para auxiliar na qualificação do pré-natal. Outra limitação foi o fato de que, apesar do município contar com 14 unidades básicas de saúde (UBS) e uma unidade de referência para o programa da mulher, nosso estudo utilizou apenas uma delas.

\section{CONSIDERACÕES FINAIS}

A percepção das gestantes, enfermeiros, docentes e discentes nesse projeto de extensão contribuiu na construção do saber e na promoção da saúde, do autocuidado e empoderamento das gestantes. Além disso, os discentes vivenciaram, tanto na prática quanto na teoria, atualização e desmistificação de conhecimentos, sendo possível, dessa maneira, o avanço do ensino-aprendizagem dos envolvidos.

Ações de extensão universitária na área da saúde bem-sucedidas visam à promoção da saúde, trocas de experiências e bons ensinamentos, e o público-alvo foram as gestantes e familiares, com a participação dos docentes, discentes e profissionais de saúde. Nesse sentido, há sensação de contentamento, além do sentimento de ter fortalecido o saber técnico e popular.

Portanto, sugere-se a continuidade desse projeto com a inclusão de outras UBS e também com outros participantes, tais como gestores.

\section{FINANCIAMENTO}

Esse projeto de extensão e cultura recebeu financiamento de setores público e privados da cidade de Jataí-GO. 


\section{AGRADECIMENTO}

Aos ACS e profissionais da ESF das áreas 317 e 309 do município do projeto de extensão desenvolvido.

\section{REFERÊNCIAS}

BARRETO, C. N. et al. O Sistema Único de Saúde que dá certo: ações de humanização no pré-natal. Rev Gaúcha Enferm., Porto Alegre, v. 36, n. (esp), p. 168-76, 2015. Doi: 10.1590/1983-1447.2015.esp.56769.

BARROS, F. C. et al. Global report on preterm and stillbirth (3 of 7): evidence for effectiveness of interventions. BMC Pregnancy Childbirth, v. 10, Suppl 1, p. S3, 2010. Doi: 10.1186/1471-2393-10-S1-S3.

BRASIL. Lei Orgânica da Saúde. Lei no 8.080, de 19 de setembro de 1990. Dispõe sobre as condições para a promoção, proteção e recuperação da saúde, a organização e o funcionamento dos serviços correspondentes e dá outras providências. Disponível em: https://www.saude.mg.gov.br/images/documentos/Lei\%20Federal\%20N\%208080\%201990.p df. Acesso em: 20 maio 2019.

Brasil. Ministério da Saúde. Secretaria de Atenção à Saúde. Departamento de Ações Programáticas Estratégicas. Área Técnica de Saúde da Mulher. Pré-natal e Puerpério: atenção qualificada e humanizada. Brasília, DF: MS, 2005. 163 p. (Série A. Normas e Manuais Técnicos; Série Direitos Sexuais e Direitos Reprodutivos - Caderno no ${ }^{5}$ ).

BRASIL. Ministério da Saúde. Secretaria de Atenção à Saúde. Departamento de Atenção Básica. Atenção ao pré-natal de baixo risco. Brasília, DF: MS, 2012. 318 p. (Série A. Normas e Manuais Técnicos; Cadernos de Atenção Básica, nº 32)

BRASIL. Ministério da Saúde. Secretaria Executiva. Programa de Humanização do Parto: humanização no pré-natal e nascimento. Brasília, DF: Ministério da Saúde, 2002.

DIAS, E. G. et al. Ações do enfermeiro no pré-natal e a importância atribuída pelas gestantes. Sustinere, Rio de Janeiro, v. 6, n. 1, p. 52-62, 2018. Doi: 10.12957/sustinere.2018.31722.

DIAS, E. G. et al. Percepção das gestantes quanto à importância das ações educativas promovida pelo enfermeiro no pré-natal em uma unidade básica de saúde. G\&S, Brasília, v. 6, n. 3, p. 2.695-2.710, 2015. Disponível em: https://periodicos.unb.br/index.php/rgs/article/view/3151/2837. Acesso em: 4 jun. 2020.

DOMINGUES, D. M.; JORDÃO, M. E.; DE CASTILHO, M. A. Conhecimento, aprendizagem e socialização da extensão no contexto do laboratório de história da Universidade Católica Dom Bosco (UCDB). Em Extensão, Uberlândia, v. 18 n. 1, p. 187195, jan./jun. 2019. Doi: 10.14393/REE-v18n12019-46253.

DOMINGUES, R. M. S. M. et al. Avaliação da adequação da assistência pré-natal na rede SUS do Município do Rio de Janeiro, Brasil. Cad. Saúde Pública, Rio de Janeiro, v. 28, n. 3, p. 425-437, mar. 2012. Doi: 10.1590/S0102-311X2012000300003. 
FALCONE, V. M. et al. Atuação multiprofissional e a saúde mental de gestantes. Rev. Saúde Pública [online], v. 39, n. 4, p. 612-618, 2005. Doi: 10.1590/S0034-89102005000400015.

FARIAS, K. V. O. et al. Projeto de extensão "Bem Gestar": a extensão como ferramenta para a educação em saúde no ciclo gravídico-puerperal. Em Extensão, Uberlândia, v. 18 n. 1, p. 165-175, jan./jun. 2019. Doi: 10.14393/REE-v18n12019-46145.

GANDOLFI, F. R. R. et al. Mudanças na vida e no corpo da mulher durante a gravidez. BJSCR, Curitiba, v. 27, n. 1, p. 126-131, 2019. Disponível em: https://www.mastereditora.com.br/periodico/20190607_200629.pdf. Acesso em: [04 jun 2020].

GUERREIRO, E. M. et al. Educação em saúde no ciclo gravídico-puerperal: sentidos atribuídos por puérperas. Rev. Bras. Enferm., Brasília, v. 67, n. 1, p. 13-21, 2014. Doi: 10.5935/0034-7167.20140001.

LANDERDAH, M. C. et al. Percepção de mulheres sobre atenção pré-natal. Esc Anna Nery R Enferm., Rio de Janeiro, v. 11, n. 1, p. 105-111, 2007. Disponível em: https://www.scielo.br/pdf/ean/v11n1/v11n1a15. Acesso em: 15 mar. 2020.

LEAL, M. C. et al. Assistência pré-natal na rede pública do Brasil. Rev. Saúde Pública, São Paulo, v. 54, n. 8, p. 1-12, 2020. Doi: 10.11606/s1518-8787.2020054001458.

LEITE, M. G. et al. Sentimentos advindos da maternidade. Psicologia em Estudo, Maringá, v. 19, n. 1, p. 115-124, jan./mar. 2014. Doi: 10.1590/1413-7372217650011.

LIVRAMENTO, D. V. P. et al. Percepções de gestantes acerca do cuidado pré-natal na atenção primária à saúde. Rev. Gaúcha Enferm., Porto Alegre, v. 40, e20180211, p. 1-9, 2019. Doi: 10.1590/1983-1447.2019.20180211.

MARTINS, M. F. S. V.; REMOALDO, P. C. A. C. Representações da enfermeira obstetra na perspectiva da mulher grávida. Rev. Bras. Enferm., Brasília, v. 67, n. 3, p. 360-5. maio-jun. 2014. Doi: 10.5935/0034-7167.20140047.

MARTINS, Q. P. M. et al. Conhecimentos de gestantes no pré-natal: evidências para o cuidado de enfermagem. Sanara: Revista de Políticas Públicas, Sobral, v. 14, n. 2, p. 65-71, 2015. Disponível em: https://sanare.emnuvens.com.br/sanare/article/viewFile/827/498. Acesso em: 15 mar. 2020.

PICCININI, C. A. et al. Gestação e a constituição da maternidade. Psicol estud., Maringá, v. 13, n. 1, p. 63-72, 2008. Doi: 10.1590/S1413-73722008000100008.

POLGLiANE, R. B. S. et al. Adequação do processo de assistência pré-natal segundo critérios do Programa de Humanização do Pré-natal e Nascimento e da Organização Mundial de Saúde. Ciência \& Saúde Coletiva, Rio de Janeiro, v. 19, n. 7, p. 1999-2010, 2014. Doi: 10.1590/1413-81232014197.08622013

ROCHA, A. C.; ANDRADE, G. S. Atenção da equipe de enfermagem durante o pré-natal: percepção das gestantes atendidas na rede básica de Itapuranga-GO em diferentes contextos sociais. Enfermagem Contemporânea, Salvador, v. 6, n. 1, p. 30-41, 2017. Doi:

10.17267/2317-3378rec.v6i1.1153. 
SILVA, L. S. et al. Análise das mudanças fisiológicas durante a gestação: desvendando mitos. Revista Faculdade Montes Belos, v. 8, n. 1, 2015, p. 1-16, 2014. Disponível em: http://revista.fmb.edu.br/index.php/fmb/article/view/11/8. Acesso em: 4 jun. 2020.

SILVA, M. Z. N. et al. Acesso e acolhimento no cuidado pré-natal à luz de experiências de gestantes na Atenção Básica. Saúde Debate, Rio de Janeiro, v. 38, n. 103, p. 805-816, out./dez., 2014. Doi: 10.5935/0103-1104.20140073.

TRAESEL C. A. Educação em saúde: fortalecendo a autonomização do usuário. São Paulo: Hucitec, 2004.

VIEIRA, S. M. et al. Percepção das puérperas sobre a assistência prestada pela equipe de saúde no pré-natal. Texto contexto - enferm., Florianópolis, v. 20, n. spe, p. 255-262, 2011. Doi: 10.1590/S0104-07072011000500032.

VIELLAS, E. F. et al. Assistência pré-natal no Brasil. Cad. Saúde Pública, Rio de Janeiro, v. 30, supl. 1, p. S85-S100, 2014. Doi: 10.1590/0102-311X00126013.

Submetido em 20 de abril de 2020.

Aprovado em 16 de junho de 2020. 